voorafgaand aan afbouw (Lamberink et al., 2017).

5 Is het mogelijk om bij een individuele patiënt de recidiefkans na afbouw te berekenen?

Ja; we hebben een predictiemodel ontwikkeld voor de recidiefkans na twee en vijf jaar, en voor aanvalsvrijheid na tien jaar (Lamberink et al., 2017). Een praktische rekentool hiervoor is beschikbaar op www.epilepsypredictiontools.info.
Tot slot

Of bij een aanvalsvrije patiënt wel of niet wordt overgegaan tot het afbouwen van medicatie blijft een individuele en zorgvuldige afweging van voordelen en risico's, die door patiënt, ouders en behandelaar gezamenlijk moet worden gemakt. De resultaten van het hierna te bespreken onderzoek kunnen helpen om tot een beter gefundeerd besluit te komen.

\title{
Vroege medicatie-afbouw na
} kinderepilepsiechirurgie: veilig en voordelig

In de loop van de tijd is de visie ten aanzien van afbouw van anti-epileptica na kinderepilepsiechirurgie veranderd. Hier wordt het onderzoek beschreven dat is gedaan naar het effect van afbouw van anti-epileptica bij deze kinderen. Ook wordt aangegeven hoe het resultaat van dit onderzoek heeft bijgedragen aan de verandering van het postoperatieve medicatiebeleid.

Tot voor kort werden kinderen minimaal twee jaar doorbehandeld na epilepsiechirurgie. Dit naar analogie van het afbouwbeleid bij medicamenteus behandelde patiënten. Goede studies om dit beleid te onderbouwen ontbraken en resultaten uit de literatuur spraken elkaar tegen. Uit een kleine Nederlandse cohortstudie bleek dat vroege afbouw van anti-epileptica (AE) niet geassocieerd is met het recidiveren van aanvallen, maar dat het optreden van een recidief afhankelijk is van andere determinanten, zoals incomplete resectie (Boshuisen et al., 2009). In deze studie kon niet worden onderzocht welke factoren invloed hebben op lange termijn-aanvalsvrijheid en deze vraag blijft ook in de literatuur onbeantwoord, evenals de vraag of afbouw van $\mathrm{AE}$ daar wel een rol in speelt. Het is inmiddels bekend dat het percentage patiënten dat aanvalsvrij blijft na operatie, daalt bij langere follow-up (Garcia et al., 20I5), wat waarschijnlijk afhankelijk is van de onderliggende epileptogene pathologie en van het $\mathrm{AE}$-afbouwbeleid (Lamberink et al., 20I5b, Garcia et al., 2015). Een causale relatie tussen $\mathrm{AE}$-afbouw en het recidiveren van aanvallen is echter nooit aangetoond. Mogelijk wordt juist door afbouw van medicatie duidelijk welke patiënten echt $\mathrm{AE}$ nodig hebben en welke patiënten zonder kunnen. In dat geval zou vroege $\mathrm{AE}-$ afbouw eerder incompleet chirurgisch succes kunnen aantonen maar ook onnodig medicatiegebruik bij veel kinderen kunnen voorkomen. Dit laatste is wenselijk om de nadelige cognitieve bijwerkingen van $\mathrm{AE}$ te voorkomen.

In de TimeToStop (TTS) studie werd onderzoek gedaan naar $\mathrm{AE}$-afbouw in relatie tot het recidiveren van aanvallen en lange termijn-aanvalsvrijheid. Daarnaast werden twee studies uitgevoerd waarin we de relatie tussen AE-afbouw en cognitieve uitkomst hebben bestudeerd.

\section{Time'ToStop studie}

De TimeToStop studie is een Europese multicenterstudie waaraan 766 kinderen uit vijftien centra deelnamen, die na epilepsiechirurgie aanvalsvrij werden en bij wie de medicatie werd afgebouwd (Boshuisen et al., 2012). In deze studie werd de relatie tussen de timing van het afbouwen van $\mathrm{AE}$ en het optreden van I) een recidiefaanval, 2) aanvalsvrijheid ten tijde van laatste follow up, gedefinieerd als aanvalsvrijheid gedurende minimaal één jaar onafhankelijk van AE-gebruik (Engel I of ILAE I) en 3) cure ten tijde van laatste follow up, gedefinieerd als aanvals- en medicatievrijheid, gedurende minimaal één jaar.

Het mediane interval tot de start van de medicatie-afbouw was I2.5 maanden en 28.8 maanden tot het geheel staken 


\begin{tabular}{|c|c|c|c|c|}
\hline \multicolumn{5}{|c|}{ Recidief tijdens of na AE-afbouw } \\
\hline \multicolumn{3}{|c|}{ ruw model } & \multicolumn{2}{|c|}{ geadjusteerd model } \\
\hline & $\operatorname{HR}(95 \% \mathrm{CI})$ & p-waarde & $\mathrm{HR}(95 \% \mathrm{CI})$ & p-waarde \\
\hline TTA (per 3 maanden) & $0.95(0.90-1.00)$ & 0.05 & $0.94(0.89-\mathrm{I} .00)$ & 0.05 \\
\hline TTS (per 3 maanden) & 0.91 ( $0.85-0.98)$ & $0.0 \mathrm{I}$ & $0.90(0.83-0.98)$ & 0.02 \\
\hline \multicolumn{5}{|c|}{ Aanvalsvrij aan het einde van de studie (Engel I >r jaar) } \\
\hline \multicolumn{3}{|c|}{ ruw model } & \multicolumn{2}{|c|}{ geadjusteerd model } \\
\hline & $\operatorname{HR}(95 \% \mathrm{CI})$ & p-waarde & HR (95\% CI) & p-waarde \\
\hline TTA (per 3 maanden) & I.OI (0.93-I.09) & $0.9 I$ & $0.97(0.89-1.07)$ & 0.55 \\
\hline TTS (per 3 maanden) & I.04 (0.94-I.I4) & 0.42 & I.03 (0.93-I.I4) & 0.55 \\
\hline \multicolumn{5}{|c|}{ 'Cure' aan het einde van de studie (Engel I en AE vrij > I jaar) } \\
\hline \multicolumn{3}{|c|}{ ruw model } & \multicolumn{2}{|c|}{ geadjusteerd model } \\
\hline & $\operatorname{HR}(95 \% \mathrm{CI})$ & p-waarde & $\mathrm{HR}(95 \% \mathrm{CI})$ & p-waarde \\
\hline TTA (per 3 maanden) & I.00 (0.97-I.03) & 0.96 & $0.97(0.97-1.03)$ & 0.84 \\
\hline TTS (per 3 maanden) & $0.99(0.96-1.03)$ & 0.65 & $0.98(0.94-I .02)$ & 0.31 \\
\hline
\end{tabular}

Tabel 1 Geadjusteerde en ongeadjusteerde relatie tussen timing van AE-afbouw en aanvalsuitkomstmaten. Legende: p-waarde significant als $<0.05$. Cox regressie analyse, HR, hazard ratio; TTA, interval tot afbouw van AE per drie maanden; TTS, interval tot staken van AE per drie maanden. Het geadjusteerde model is gecorrigeerd voor: aantal AE ten tijde van de operatie, compleetheid van resectie van de anatomische laesie, postoperatieve EEG-bevindingen, multifocale MRI-afwijkingen, directe postoperatieve aanvalsurijheid, eerdere operatie, oorzaak van de epilepsie en type operatie.

van de medicatie. Preoperatief hadden kinderen gemiddeld $4.5 \pm 2.4$ (range o-I5) AE geprobeerd. Ten tijde van operatie gebruikten kinderen gemiddeld $\mathrm{I} .8 \pm 0.8 \mathrm{AE}$ (range 0-5). Middelen die als eerste werden afgebouwd waren primidon, vigabatrine en fenytoïne. Op het laatste follow up tijdspunt waren 4II kinderen volledig medicatievrij. Ten tijde van het laatste neuropsychologisch onderzoek was het gemiddelde aantal $\mathrm{AE}$ in de gehele groep I.I \pm 0.8 AEs (Boshuisen et al., 2015).

Recidieven traden op bij $12.5 \%$ van de kinderen en waren geassocieerd met een kortere duur tot zowel starten als compleet staken van medicatie (ffi $3 \%$ toename recidiefkans per maand eerder afgebouwd) (tabel I). Het herwinnen van aanvalsvrijheid was niet geassocieerd met timing van afbouw. Lange termijn aanvalsvrijheid werd bij 95\% van de kinderen behaald en was niet geassocieerd met de tijdsduur tot het starten van AE-afbouw of volledig staken hiervan (tabel I). Een kleinere kans op lange termijn aanvalsvrijheid was geassocieerd met een hoger aantal AE ten tijde van de operatie (HR 0.63 (0.4I-0.97)) en met een incomplete resectie van de laesie (HR 0.40 (0.17-0.93)). De kans op cure was verlaagd bij preoperatief gebruik van meer AE (HR 0.8I (0.70-0.94)), incomplete resectie (HR $0.64(0.47-0.88))$ en bij een eerdere operatie in de voorgeschiedenis (HR 0.60 (0.36-I.00)). Hemisferectomiepatiënten hadden een hogere kans op cure (HRI.70 (I.oI2.85)). Samenvattend vonden we dat vroege AE-afbouw geen invloed had op de lange termijn aanvalsvrijheid en medicatievrijheid, en dat timing van AE-afbouw niet gerelateerd was aan de kans op herwinnen van aanvalsvrijheid. Vroege afbouw zou daarmee inderdaad incompleet succes van de operatie eerder ontmaskeren en onnodig langdurig AE-gebruik bij veel kinderen voorkomen. Om te bestuderen wat de voordelen van AE-afbouw na epilepsiechirurgie bij kinderen zijn werden twee studies uitgevoerd naar de cognitieve effecten hiervan. In de eerste studie (Van Schooneveld et al., 2013) werd de impact van postoperatieve $\mathrm{AE}$-afbouw op reactietijden onderzocht bij 57 kinderen die na operatie aanvalsvrij waren. Scores op vier reactiesnelheidstesten, I2 en 24 maanden na operatie uitgevoerd, werden vergeleken met postoperatieve baselinemetingen zes maanden na de operatie. Vierentwintig maanden na de operatie hadden de kinderen die hun medicatie hadden afgebouwd significant meer verbetering van hun reactiesnelheid dan de kinderen zonder medicatie-afbouw (reactietijd op licht: $14 \%$ meer verbetering, $p=0.03 \mathrm{I}$, op geluid: $7 \%, p=0.045$ en de motorische snelheid nam $9 \%$ meer toe, $\mathrm{p}=0.003)$. Er werd geconcludeerd dat medicatieafbouw na de operatie de reactiesnelheid verbetert en daarmee het potentieel voor cognitieve verbetering verhoogt. In de tweede studie werd voor de subgroep van het TTScohort met beschikbare pre- en postoperatieve neuropsychologische data $(n=301)$ onderzocht of AE-afbouw effect heeft op het postoperatieve IQ, en op de postoperatieve 


\begin{tabular}{|c|c|c|c|c|}
\hline & \multicolumn{2}{|c|}{ laatste postoperatieve IQ } & \multicolumn{2}{|l|}{ delta $\mathrm{IQ}^{\$}$} \\
\hline & \multicolumn{2}{|c|}{ geadjusteerd model` } & \multicolumn{2}{|c|}{ geadjusteerd model ${ }^{\star}$} \\
\hline & $\mathrm{RC}(95 \% \mathrm{CI})$ & p-waarde & $\mathrm{RC}(95 \% \mathrm{CI})$ & p-waarde \\
\hline Start afbouw van $\mathrm{AE}(\mathrm{n}=\mathrm{I} 55 / 30 \mathrm{I})$ & $3.4(0.6,6.2)$ & 0.018 & $4.5(\mathrm{I} .7,7.4)$ & 0.002 \\
\hline Compleet staken van $\mathrm{AE}(\mathrm{n}=6 \mathrm{I} / 30 \mathrm{I})$ & $4.8(\mathrm{I} .4,8.3)$ & 0.006 & 5.I (I.5, 8.7) & 0.006 \\
\hline Aantal AE afgebouwd\# (n=30I) & $2.2(0.6,3.7)$ & 0.007 & $2.6($ I.o, 4.2$)$ & 0.001 \\
\hline
\end{tabular}

Tabel 2 AE-afbouw en postoperatief IQ en delta IQ. Legenda: RC, regressie co-efficiënt, geeft de verandering in IQ of delta IQ met elke punt of categorie verandering van de predictor; CI; confidence interval. Uitgevoerde analyse: lineaire regressie analyse van de relatie tussen AE-afbouw en IQ en delta IQ. \$Postoperatief IQ min preoperatief IQ; * *geadjusteerd voor leeftijd ten tijde van operatie, interval tot laatste postoperatieve neuropsychologische onderzoek, duur van de epilepsie, geslacht en in de analyse van het laatste postoperatieve IQ, ook voor preoperatief IQ. Daarnaast werd geadjusteerd voor een 'compound propensity score' waarin factoren werden verwerkt die van invloed waren op de start van de AE-afbouw (aantal AE ten tijde van operatie, complete resectie van de anatomische laesie en de epileptogene zone, postoperatieve EEG-bevinden en etiologie). Vanwege de hoge correlatie tussen type operatie en preoperatief IQ, is er niet geadjusteerd voor type operatie. " De verandering in aantal AE ten opzichte van preoperatief.

IQ-verandering (Boshuisen et al., 20I5a). Starten met medicatie-afbouw, het aantal AE dat werd verminderd en het geheel staken van $\mathrm{AE}$ waren alle geassocieerd met zowel een hoger postoperatief IQ als met een postoperatieve IQ-verbetering, onafhankelijk van andere factoren die van invloed zijn op cognitief herstel na de operatie (tabel 2).

\section{Discussie en conclusies}

Vroege AE-afbouw na epilepsiechirurgie verhoogt bij kinderen het risico op een recidief. Dit heeft echter geen invloed op lange termijn aanvalsvrijheid of cure. Het is niet waarschijnlijk dat het iets verhoogde risico op een recidief daadwerkelijk wordt veroorzaakt door de vroegere AE-afbouw. Patiënten die hun AE later afbouwen hebben immers langer 'bewijs van chirurgisch succes' laten zien, en daardoor per definitie een lager recidiefrisico wanneer ze beginnen met $\mathrm{AE}$-afbouw. Kinderen met een vroeg recidief nog voordat aan AE-afbouw is begonnen - zouden niet in de studie zijn geïncludeerd. Ondanks de geringe invloed van timing van $\mathrm{AE}$-afbouw op een recidiefrisico heeft de studie overtuigend laten zien dat vroege afbouw de uiteindelijke kans op aanvalsvrijheid niet nadelig beïnvloedt. Deze resultaten zijn veelbelovend, ook omdat ze zijn gebaseerd op een studie van een groot cohort. De studieopzet heeft echter ook nadelen; door het retrospectieve design van de studie moeten de resultaten met enige voorzichtigheid worden geïnterpreteerd en zijn ze niet generaliseerbaar naar alle patiënten die kandidaat zijn voor epilepsiechirurgie. Er moet bijvoorbeeld rekening gehouden worden met het feit dat geïncludeerde kinderen reeds gestart waren met $\mathrm{AE}$-afbouw en daarom een relatief gunstige groep representeren. Risicofactoren voor een recidief zouden onder-gerepresenteerd kunnen zijn in onze groep. Daarnaast had maar 3,5\% van ons studiecohort een ongunstige lange termijn-uitkomst. Misschien is dit aantal te klein om subtiele verschillen in uitkomst aan te tonen. Ondanks de beperkingen van de studies is het waarschijnlijk dat vroege postoperatieve $\mathrm{AE}$-afbouw veilig is in relatie tot lange termijn aanvalsvrijheid, en dat het voordelig is voor de cognitieve uitkomst. De hier gepresenteerde cognitieve studieresultaten (zie tabel 2) tonen immers aan dat $\mathrm{AE}$-afbouw beter is voor het uiteindelijke IQ en de mate van stijging van het IQ na de operatie. Aanvalsrecidieven worden niet veroorzaakt, maar eerder ontmaskerd door AE-afbouw en reageren vaak goed op herstart van medicatie.

De uitkomsten van ons onderzoek hebben wereldwijd tot een veranderde visie op postoperatief AE-beleid bij kinderen geleid. In vragenlijst-studies in de Verenigde Staten en Canada was al gezien dat medicatie in de laatste jaren vroeger wordt afgebouwd (Swisher et al., 2013). Onze eigen historische cohortstudie van alle in Nederland geopereerde kinderen toonde ook dat er steeds vroeger wordt gestart met afbouwen, zonder dat het percentage aanvalsvrijheid daardoor beïnvloed lijkt te worden (Lamberink et al., 20I5a). Daarnaast is er een duidelijk effect van de uitkomsten van de studies op de wensen van de ouders van geopereerde kinderen. Geen enkele ouder wilde deelnemen aan de door ons geplande TTS-trial (Boshuisen et al., 2015b), waarin we hier besproken bevindingen prospectief hadden willen bevestigen. Ouders wilden niet het risico lopen gerandomiseerd te worden voor de late AE-onttrekkings-arm, waarin pas na twaalf maanden werd gestart met afbouw, in vergelijking met na vier maanden in de vroege arm. De voordelen van vroege medicatieafbouw na geslaagde epilepsiechirurgie bij kinderen bleken te overtuigend. Inmiddels wordt in het Universitair Medisch Centrum Utrecht bij kinderen zonder voorspellers voor een slechte uitkomst (zoals een incomplete resectie) al na vier maanden postoperatieve aanvalsvrijheid gestart met $\mathrm{AE}$-afbouw. 